\title{
H AND O ATOM DETECTION FOR COMBUSTION APPLICATIONS: STUDY OF QUENCHING AND LASER PHOTOLYSIS EFFECTS
}

\author{
U. MEIER, K. KOHSE-HÖINGHAUS and Th. JUST \\ DFVLR - Institut für Physikalische Chemie der Verbrennung, D-7000 Stuttgart, West Germany
}

Received 10 February 1986; in final form 7 March 1986

\begin{abstract}
A method is in development which should allow the determination of absolute number densities of $\mathrm{H}$ and $\mathrm{O}$ atoms in flames from two-photon laser-excited fluorescence measurements. The calibration will be based on reference experiments in a discharge-flow reactor. In this study, the influence of fluorescence quenching and the generation of additional $\mathrm{H}$ and $\mathrm{O}$ atoms by laser photolysis of the flame gases is investigated. Consequences for typical hydrogen-oxygen flame conditions are discussed.
\end{abstract}

\section{Introduction}

The knowledge of hydrogen and oxygen atom number densities in flames is of fundamental interest for the understanding of the chemical kinetics of combustion processes. Therefore, non-intrusive diagnostic tools are required which provide spatially resolved absolute concentrations of these atomic spe. cies. For combustion applications, previous investigations have mostly used two-photon excitation of a suitable atomic level by intense tunable UV laser radiation followed either by detection of the fluorescence [1-4] or the ionisation signal after absorption of a third photon [5-7]. Furthermore, several experiments applying resonant three-photon excitation with subsequent fluorescence of optogalvanic detection have been reported $[8-10] . \mathrm{H}$ and $\mathrm{O}$ atoms were monitored under quite different flame conditions in low-pressure $[2,8]$ and atmospheric $[5-7,10]$ hydrogen flames as well as in some atmospheric hydrocarbon flames $[3,4,9]$.

All the reported methods, however, are subject to difficulties in deriving absolute atom number densities from fluorescence or ionisation signals. An attempt has been made to use an indirect calibration technique [7]. In this paper, we describe an approach to calibrate two-photon excited fluorescence signals in flames using measurements of known concentrations of $\mathrm{H}$ and $\mathrm{O}$ atoms generated in a discharge-flow system.

For the application of this calibration method in a flame, the efficiency of fluorescence quenching by the various species present in the detection region must be known. We have used a versatile dischargeflow system for the determination of quenching rate constants for relevant species in flame gases. Since quenching rate constants may be temperature-dependent $[11,12]$, some of these experiments have been performed at elevated temperatures. Most of the quenching data reported here have been determined in this work for the first time.

It has been pointed out $[4,7]$ that multiphoton excitation techniques may suffer from complications by laser photolysis due to the high laser power densities required for the excitation. For example, 0 atoms may be produced by photodissociation of oxygencontaining compounds [4], leading to erroneous concentration measurements. Therefore, we investigated laser-induced photolytic production of $\mathrm{H}$ and $\mathrm{O}$ atoms from different parent molecules.

On the basis of our experimental data, we show how meásured fluorescence profiles may be converted into absolute concentration profiles, taking both the influence of quenching and of laser photolytic production of additional atoms into account. 


\section{Experimental}

The experimental arrangement is shown in fig. 1. Oxygen and hydrogen atoms were generated in a thermostatted discharge-flow reactor described earlier [13]. Two-photon excitation was performed using tunable UV radiation from a Nd : YAG pumped, frequency-doubled dye laser. From the observation volume at the downstream end of the flow tube, fluorescence was collected by a $f / 3.75$ quartz lens and a suitable interference filter. The fluorescence signal received by the photomultiplier (Hamamatsu R928) was processed by a boxcar integrator or alternatively by a transient digitizer for experiments where time resolution was required. Simultaneously, the laser pulse was recorded by a fast calibrated vacuum photodiode. Its pulse served as a trigger source for the detection electronics; in addition, it provided a measure of the laser intensity.

Known concentrations of $\mathrm{H}$ and $\mathrm{O}$ atoms were produced using well-known gas-phase titration schemes (e.g., ref. [14]). $O$ atoms were generated by the fast reaction

$\mathrm{N}+\mathrm{NO} \rightarrow \mathrm{O}+\mathrm{N}_{2}$.

$\mathrm{N}$ atoms were obtained by dissociation of $\mathrm{N}_{2}$ in a microwave discharge of typically $40 \mathrm{~W}$ power in a flow of 0.5 to $1 \mathrm{l} / \mathrm{min}$ (NTP) of He as a carrier gas containing about $10 \% \mathrm{~N}_{2}$. The pressure in the flow reactor was usually about 1 mbar. $\mathrm{H}$ atoms were produced by dissociation of $\mathrm{H}_{2}$ in a microwave discharge. Typical conditions were a flow of $1-2 \mathrm{l} / \mathrm{min}$ (NTP)

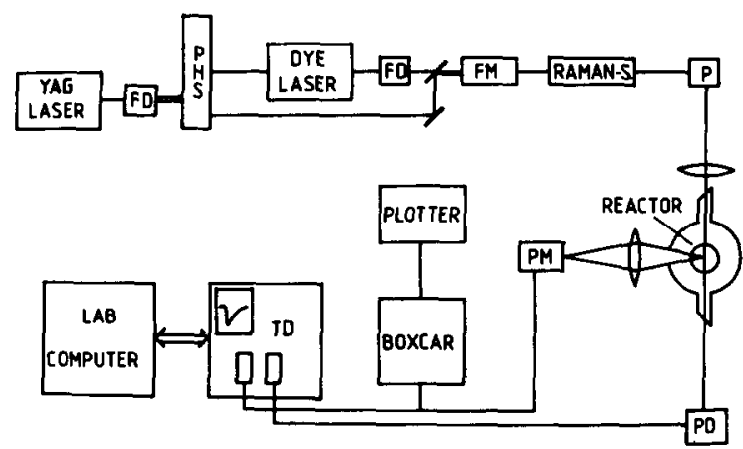

Fig. 1. Experimental arrangement. FD: frequency-doubling unit, PHS: prism harmonic separator, FM: frequency-mixing unit, RAMAN-S: Raman-shifter, P: Pellin-Broca prism, PM: photomultiplier, PD: photodiode, TD: transient digitizer.
He with $2 \% \mathrm{H}_{2}$ and a pressure of $2-3$ mbar. The $\mathrm{H}$ atom concentrations were obtained by titration with $\mathrm{NO}_{2}$ :

$\mathrm{H}+\mathrm{NO}_{2} \rightarrow \mathrm{OH}+\mathrm{NO}$.

$\mathrm{H}$ and $\mathrm{O}$ atoms were excited in a similar manner as described in ref. [2] and ref. [3], respectively. The dye laser was operated with a mixture of rhodamine $6 \mathrm{G}$ and rhodamine 640 . For the excitation of 0 atoms, its frequency-doubled output was mixed with the residual $1.06 \mu \mathrm{m}$ radiation from the Nd : YAG laser. This delivered a pulse energy of about $3 \mathrm{~mJ}$ at $226 \mathrm{~nm}$. For the detection of hydrogen atoms, the frequency-mixed output was tuned to $224 \mathrm{~nm}$ and further Raman-shifted in $\mathrm{H}_{2}$. Using the first antiStokes line, we obtained about $50-70 \mu \mathrm{J}$ per pulse at $205 \mathrm{~nm}$. The laser radiation was focused about $5 \mathrm{~mm}$ below the end of the flow tube, resulting in peak power densities of about $1.5 \mathrm{GW} / \mathrm{cm}^{2}$ for $\mathrm{O}$ atom excitation and $70 \mathrm{MW} / \mathrm{cm}^{2}$ for $\mathrm{H}$ atom excitation.

\section{Results}

\subsection{Excitation and detection}

The following excitation-detection schemes were used: For the $\mathrm{O}$ atom experiments, the $2 \mathrm{p}^{3} \mathrm{P}$ $3 p^{3} \mathrm{p}$ transition was excited. Within the bandwidth of the laser, only three lines originating from the three different fine-structure components of the ground state could be resolved. The fluorescence was observed in the $3 \mathrm{p}^{3} \mathrm{P}-3 \mathrm{~s}^{3} \mathrm{~S}$ transition at $845 \mathrm{~nm}$. The lines corresponding to the $J=2,1,0$ levels of the ground state showed an intensity ratio of $11.9: 3.4: 1$, respectively. Provided the transition probabilities for the three triplet components are equal $[1,15]$, this reflects a thermal $(300 \mathrm{~K})$ distribution within experimental error. Under room-temperature conditions, similar results have been obtained in a plasma reactor [16], whereas in flames, different line intensity ratios have been reported $[4,6]$, which did not correspond to the thermal distributions at the respective flame temperatures. For sensitivity reasons, we performed all measurements using the strongest transition which originates from $J=2$. Onset of saturation of the two-photon transition was observed at laser power densities higher than $250 \mathrm{MW} / \mathrm{cm}^{2}$. With the absolute cross 
section given in ref. [1], a saturation limit of this order of magnitude may be estimated for our experimental conditions. For all following measurements, power densities well below the saturation limit were used. In flames, energy transfer from the $03 \mathrm{p}^{3} \mathrm{P}$ to the $3 p{ }^{5} \mathrm{P}$ state has been observed $[2,17]$, resulting in $\left({ }^{5} \mathrm{P} \_{ }^{5} \mathrm{~S}\right)$ fluorescence at $777 \mathrm{~nm}$. For our usual flow reactor conditions at about 1 mbar, the collision-induced fluorescence could not be observed; at 4 mbar, a comparatively small signal at $777 \mathrm{~nm}$ appeared. $\mathrm{H}$ atoms were excited in the $n=1-n=3$ transition. Fluorescence was detected at $656 \mathrm{~nm}(n=3-n=2)$. We did not find any saturation behaviour due to the much lower laser intensity compared to the $\mathrm{O}$ atom experiment. We also tried to generate three-photon induced fluorescence. No signals were found under our low-pressure conditions, neither for $n=1-n=3$ nor for $n=1-n=4$ excitation.

\subsection{Lifetimes and quenching}

Quenching rate constants were determined from fluorescence decay curves at different quencher concentrations. Fig. 2 shows a typical fluorescence decay

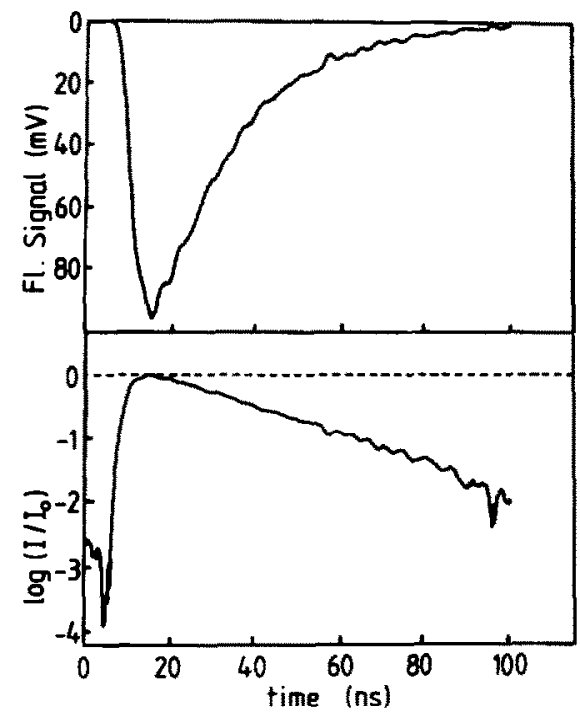

Fig. 2. H atom fluorescence signal versus time. Top: linear scale, bottom: logarithmic scale (base 10). Reactor conditions: He: $900 \mathrm{~cm}^{3} / \mathrm{min}, \mathrm{H}_{2}: 17 \mathrm{~cm}^{3} / \mathrm{min}, p=3.85 \mathrm{mbar}, T=360$ K. From the slope in the lower diagram, an effective lifetime of $19.8 \mathrm{~ns}$ was determined. Correcting this by the effect of quenching by $\mathrm{H}_{2}$, a natural lifetime of $21 \mathrm{~ns}$ is obtained. for $\mathrm{H}$ atoms without additional quencher. To derive effective lifetimes from such curves, the signal was evaluated starting at about $10 \mathrm{~ns}$ after the laser pulse (which had a half-width of $3.5 \mathrm{~ns}$ ); typically a range of 3 to 4 lifetimes was covered. Under the particular conditions used for the experiment in fig. 2 , an effective lifetime of $19.8 \mathrm{~ns}$ is obtained. From this value, the radiative lifetime $\tau_{0}$ of the transition can be derived, if quenching rate constants by $\mathrm{He}$ and $\mathrm{H}_{2}$ are known. In this case, $\tau_{0}$ is $21 \mathrm{~ns}$. From many experiments under different conditions, an average $\tau_{0}$ of $21.5 \pm 1.5 \mathrm{~ns}$ was obtained. This is in good agreement with a literature value of $22.7 \mathrm{~ns}$ [18]. Similarly, an average lifetime $\tau_{0}$ of $37.2 \pm 3.3 \mathrm{~ns}$ was found in the $O$ atom experiments. It should be noted that the lifetime was not dependent on the $O$ atom production method. In addition to the way of production describ. ed above, we generated $\mathrm{O}$ atoms in a microwave discharge in a mixture of $\mathrm{O}_{2}$ and $\mathrm{He}$ or by photolyzing $\mathrm{NO}_{2}$ diluted in He under static or flow conditions. The results of these experiments are included in the $\tau_{0}$ values given above. Previously, lifetimes in the range of $36[18,19]$ to $39 \mathrm{~ns}[1,20]$ have been reported.

The room-temperature quenching rate constants obtained by measuring effective lifetimes at different quencher concentrations are listed in table 1 . The error bars correspond to the statistical error (one standard deviation). The example of $\mathrm{H}$ atom quenching by $\mathrm{H}_{2}$ shows the reproducibility from two independent determinations. We estimate our experimental error to be about $\pm 20 \%$ for the room-temperature quenching rate constants. Only few literature data are available for comparison. The quenching rate constant of $O$ by $\mathrm{N}_{2}$ given in ref. [1] is $30 \%$ lower than ours. We do not know the reason for this slight discrepancy. For $\mathrm{H}_{2} \mathrm{O}$ as collision partner, our data may be compared with those of ref. [21]. Whereas the quenching rate constants for the $\mathrm{H}$ atom are in close agreement, a large discrepancy is found for the case of $\mathrm{O}$ atom quenching by $\mathrm{H}_{2} \mathrm{O}$. For the latter, however, the natural lifetime obtained in ref. [21] is not correct, and the plot of inverse lifetime versus $\mathrm{I}_{2} \mathrm{O}$ concentration is curved, so that this evaluation may be doubtful.

The quencher molecules used in this work were chosen in view of their relevance for the atom detection in hydrogen or hydrocarbon flames. Some examples for the quenching of $\mathrm{H}$ and $\mathrm{O}$ atoms at 
Table 1

Room-temperature quenching rate constants for the $O 3 \mathrm{p}^{3} \mathrm{P}$ and $\mathrm{H}(n=3)$ states, respectively

\begin{tabular}{llll}
\hline Atom & $\begin{array}{l}\text { Collision } \\
\text { partner }\end{array}$ & $\begin{array}{l}k_{\mathrm{Q}} \\
\left(\mathrm{cm}^{3} \mathrm{~s}^{-1}\right)\end{array}$ & $\begin{array}{l}\text { Previous } \\
\text { investigations }\end{array}$ \\
\hline $\mathrm{O}$ & $\mathrm{Hr}$ & $\begin{array}{l}\text { no effect } \mathrm{a}) \\
(1.0 \pm 0.2) \times 10^{-10}\end{array}$ & $(2.45 \pm 0.12) \times 10^{-10}[1]$ \\
& $\mathrm{N}_{2}$ & $(3.6 \pm 0.2) \times 10^{-10}$ & \\
$\mathrm{O}_{2}$ & $(3.7 \pm 0.3) \times 10^{-10}$ & $(9.4+1.5) \times 10^{-10}[21]$ \\
& $\mathrm{H}_{2}$ & $(5.9 \pm 0.6) \times 10^{-10}$ & \\
& $\mathrm{H}_{2} \mathrm{O}$ & $(4.9 \pm 0.3) \times 10^{-9}$ & \\
& $\mathrm{He}$ & no effect a) & \\
& $\mathrm{Ar}$ & $(4.6 \pm 0.5) \times 10^{-10}$ & \\
& $\mathrm{O}_{2}$ & $(2.6 \pm 0.1) \times 10^{-9}$ & $(9.1 \pm 1.6) \times 10^{-9}[21]$ \\
& $\mathrm{H}_{2}$ & $(2.2 \pm 0.1) \times 10^{-9}$ & \\
& $\mathrm{H}_{2} \mathrm{O}$ & $(1.9 \pm 0.3) \times 10^{-9}$ & \\
& $\mathrm{CH}_{4}$ & $(1.1 \pm 0.1) \times 10^{-8}$ & \\
& $\mathrm{C}_{2} \mathrm{H}_{2}$ & $(3.5 \pm 0.2) \times 10^{-9}$ & \\
& & $(5.6 \pm 0.4) \times 10^{-9}$ &
\end{tabular}

a) Within the pressure range of $0.5-10 \mathrm{mbar}$.
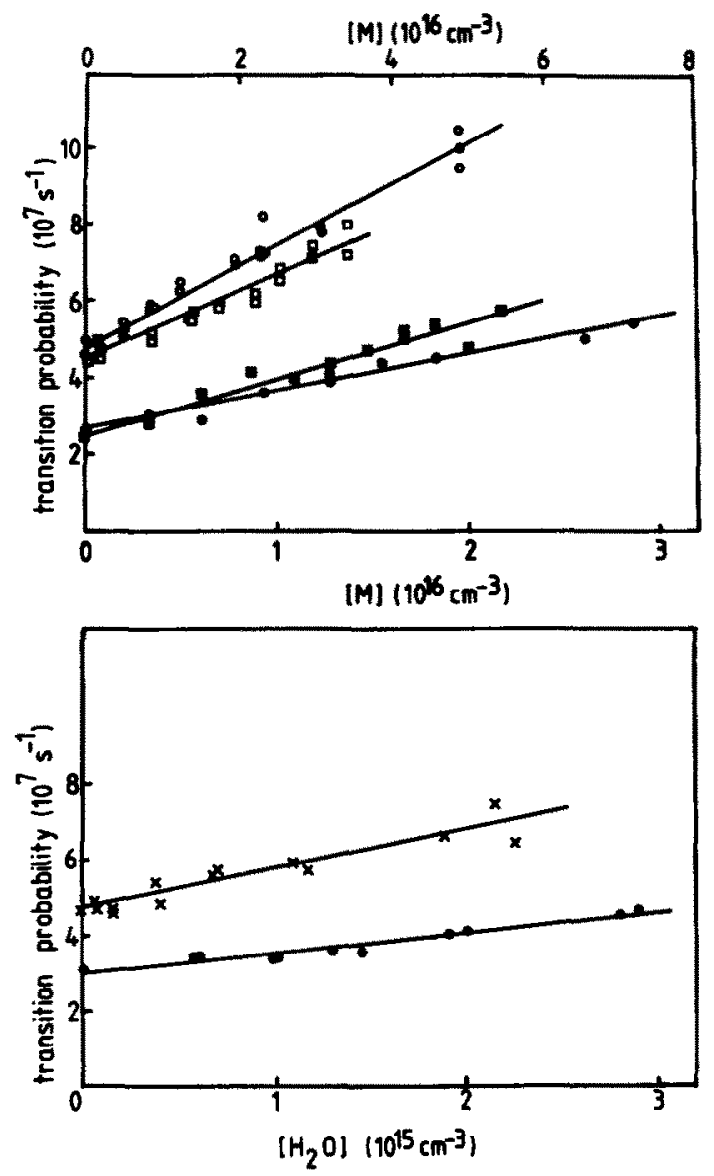

room temperature are shown in fig. 3, particularly those relevant for a hydrogen-oxygen flame. The temperature-dependent rate constants for the quenching of $\mathrm{H}$ atoms by $\mathrm{H}_{2}, \mathrm{O}_{2}$ and $\mathrm{H}_{2} \mathrm{O}$ are displayed in table 2. Here, the experimental error is estimated to be up to $30 \%$ at the elevated temreratures. In the limited range of temperatures accessible in the present arrangement, a marked dependence of the quenching rate constants on temperature was not found within experimental error.

\subsection{Laser-induced photolytic atom production}

It has been reported by Miziolek and DeWilde [4] that $\mathrm{O}$ and $\mathrm{H}$ atoms may be generated by photolysis of the flame gases even in the absence of a flame. With respect to atom concentration measurements in a flame, we investigated the possibility of creating these atoms by laser photolysis. The results are listed in table 3. The measurements were performed at the excitation wavelengths for the $\mathrm{H}$ and $\mathrm{O}$ atoms with

Fig. 3. Room-temperature quenching rate constants. Top: - quenching of $\mathrm{O}$ by $\mathrm{H}_{2}$ (upper scale), $\bullet$ quenching of $\mathrm{O}$ by $\mathrm{O}_{2}$ (upper scale), $\square$ quenching of $\mathrm{H}$ by $\mathrm{H}_{2}$ (lower scale), $\mathrm{O}$ quenching of $\mathrm{H}$ by $\mathrm{O}_{2}$ (lower scale). Bottom: $\bullet$ quenching of $\mathrm{O}$ by $\mathrm{H}_{2} \mathrm{O}$, $X$ quenching of $\mathrm{H}$ by $\mathrm{H}_{2} \mathrm{O}$. 
Table 2

Temperature-dependent quenching rate constants for the $\mathrm{H}$ $(n=3)$ state

\begin{tabular}{llr}
\hline & $T(\mathrm{~K})$ & $\begin{array}{l}10^{9} k \\
\left(\mathrm{~cm}^{3} \mathrm{~s}^{-1}\right)\end{array}$ \\
\hline $\mathrm{H}+\mathrm{H}_{2}$ & 293 & $1.9 \pm 0.3$ \\
& 311 & $2.2 \pm 0.1$ \\
& 408 & $2.2 \pm 0.1$ \\
& 473 & $1.9 \pm 0.1$ \\
& 505 & $2.3 \pm 0.2$ \\
$\mathrm{H}+\mathrm{O}_{2}$ & 623 & $2.8 \pm 0.2$ \\
& 306 & $2.6 \pm 0.1$ \\
& 498 & $3.2 \pm 0.1$ \\
& 613 & $2.9 \pm 0.2$ \\
$\mathrm{H}+\mathrm{H}_{2} \mathrm{O}$ & 698 & $2.5 \pm 0.1$ \\
& 300 & $10.5 \pm 1.1$ \\
& 373 & $8.9 \pm 0.8$ \\
& 458 & $7.9 \pm 1.1$ \\
& 560 & $8.3 \pm 2.0$ \\
\hline
\end{tabular}

the highest available laser power densities. In most cases, more than one quantum is likely to be involved in the atom production from the precursor molecule. Therefore, the quoted efficiencies may be strongly dependent on laser power density. According to the detection limits of $10^{12} \mathrm{O}$ atoms $/ \mathrm{cm}^{3}$ and $2 \times 10^{13}$ $\mathrm{H}$ atoms $/ \mathrm{cm}^{3}$, upper limits for $\mathrm{O}$ atom production from $\mathrm{OH}$ and $\mathrm{H}$ atom production from $\mathrm{H}_{2}$ and $\mathrm{H}_{2} \mathrm{O}$ are given.

Table 3

Photolysis efficiencies at the $\mathrm{O}$ and $\mathrm{H}$ atom excitation wavelengths. The upper limits correspond to a detection limit of $10^{12} \mathrm{~cm}^{-3}$ for $\mathrm{O}$ atoms and $2 \times 10^{13} \mathrm{~cm}^{-3}$ for $\mathrm{II}$ atoms

\begin{tabular}{lll}
\hline Atom & Precursor & Efficiency \\
\hline $\mathrm{O}$ & $\mathrm{NO}_{2}$ & 0.2 \\
& $\mathrm{NO}$ & $7 \times 10^{-4}$ \\
& $\mathrm{O}_{2}$ & $6 \times 10^{-6}$ \\
& $\mathrm{H}_{2} \mathrm{O}$ & $7 \times 10^{-6}$ \\
& $\mathrm{OH}$ & $\leqslant 5 \times 10^{-2}$ \\
& $\mathrm{H}_{2}$ & $\leqslant 5 \times 10^{-5}$ \\
$\mathrm{H}$ & $\mathrm{H}_{2} \mathrm{O}$ & $\leqslant 10^{-4}$ \\
\hline
\end{tabular}

\section{Discussion}

The relevance of the measured data for the determination of absolute concentrations of $\mathrm{H}$ and $\mathrm{O}$ atoms will be discussed in the first place for a hydrogen-oxygen flame. In the case of actual flame measurements, the procedure would be to derive absolute atom concentrations from measured fluorescence intensity profiles. In the following discussion, we proceed the reverse way: Starting with a given ("true") atom concentration profile from a chemical kinetic flame model, we deduce the corresponding fluorescence signal from a three-level rate equation calculation for the $\mathrm{H}$ atom. This fluorescence intensity will be compared with the fluorescence intensity under our flow reactor conditions, which corresponds to a known atom concentration. Thus we obtain necessary information for the development of a calibration procedure.

In order to discuss realistic conditions, we have chosen as an example a set of well-determined lowpressure $\mathrm{H}_{2}-\mathrm{O}_{2}-\mathrm{Ar}$ flames from the literature [22]. We have simulated these flames using a chemicalkinetic flame model [23] with most of the kinetic data taken from ref. [24].

This set of $\mathrm{H}_{2}-\mathrm{O}_{2}-\mathrm{Ar}$ flames provides us with the $\mathrm{H}$ atom concentration profiles which we regard as "true" for the course of this discussion.

With the concentrations of $\mathrm{H}_{2}, \mathrm{O}_{2}, \mathrm{H}_{2} \mathrm{O}, \mathrm{OH}, \mathrm{H}$ and $\mathrm{O}$ taken from the chemical-kinetic flame model and the efficiencies for laser photolysis from table 3 , we conclude that laser-induced photolytic production of $\mathrm{H}$ and $\mathrm{O}$ atoms will be negligible ( $\leqslant 1 \%$ of the atoms present in the flame). This implies that the power densities for the excitation do not exceed the values used for the determination of the efficiencies in table 3.

Provided that all experimental conditions regarding the laser excitation and fluorescence detection may be left unchanged when we replace the discharge flow reactor by the low-pressure burner, the remaining problem will be the different chemical environment and temperature with respect to the collisional quenching efficiencies. To account for these differences, we have calculated local effective quenching rates for $\mathrm{H}$ atoms from the quencher concentrations given by the chemical-kinetic flame model and the quenching constants in table 2 . Of course, a possible source 
of uncertainty may be the unknown quenching efficiencies at flame temperatures. Lacking experimental or theoretical data, we assumed in a first approximation that our quenching rate constants for the $\mathrm{H}$ atom may be extrapolated from the temperature regime investigated to flame temperatures. This assumption may be justified by the result that over the investigated temperature range, the rate constants in table 2 showed no marked dependence on temperature. According to these assumptions, the effective quenching rates at different heights above the burner were calculated for the reported flames at different stoichiometries [22]. They were of the order of (1-2) $\times 10^{9} \mathrm{~s}^{-1}$.

The local quenching rates are now used to derive the corresponding fluorescence intensity profiles from the given $\mathrm{H}$ atom concentration profiles. This is achieved by a rate equation calculation for the three energy levels $(n=1,2,3)$ of the $\mathrm{H}$ atom involved in the excitation-fluorescence process. We solved the three rate equations with and without additional quenching terms for different positions in the flames. The radiative transition probabilities for the $n=3$ $n=2$ and $n=3-n=1$ transitions were taken from ref. [18], the two-photon absorption cross section from ref. [1]. The fluorescence intensity calculated without quenching terms corresponds to the reactor zonditions, the fluorescence intensity with locally varying quenching efficiencies corresponds to the flame conditions.

Fig. 4 shows the results for the flame at $\Phi=1.4$ [22] obtained with this simulation. The lower curve represents the "true" $\mathrm{H}$ atom concentration as a function of the height above the burner as resulting from the chemical-kinetic flame model. An actual measured fluorescence intensity profile resulting from these concentrations would have a different shape. The distortion is due to the locally varying quenching efficiencies. This is demonstrated by the upper curve, where this quenching behaviour is disregarded; instead, a constant quenching efficiency is used. Its value was chosen so that the concentrations of both curves are arbitrarily set equal at point " $x$ ". In this case, the fluorescence intensities predicted by our three-level model for the point " $x$ " differ by a factor of 3.7 with and without quenching terms included. This corresponds to the reduction of the fluorescence intensity between the "clean" conditions of the flow reactor

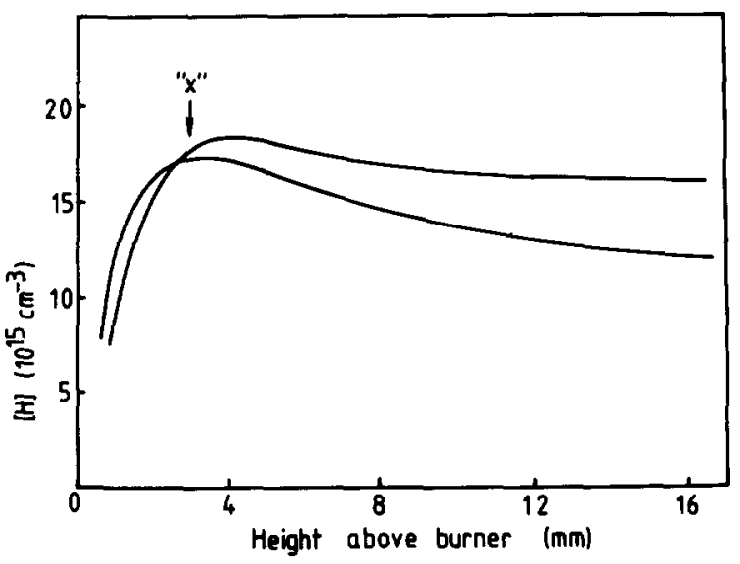

Fig. 4. Influence of quenching on $\mathrm{H}$ atom concentrations derived from fluorescence signals. $\mathrm{H}$ atom number densities as function of height above burner; lower curve: concentrations from kinetic model (see text); upper curve: concentrations that would result from a fluorescence measurement with a position-independent quenching correction. The concentrations are arbitrarily scaled to be equal at " $x$ ".

and the fast quenching environment in the flame at point " $x$ ".

In conclusion, this example shows that fluorescence signals in a flame may be converted to absolute atom concentrations by comparison with signals from known concentrations in a discharge flow reactor. However, this comparison must include the different quenching conditions in the two systems. It is insufficient to assume constant quenching rates over the en. tire flame, since in that case even a relative measurement of atom fluorescence versus height above the burner would yield erroneous atom concentrations; instead, the local variation of quenching rates due to the changing chemical environment must be carefully considered.

Using this method for the evaluation of quenching corrections with the necessary precautions discussed above, an absolute calibration may be obtained for the $\mathrm{H}$ atom number densities in a hydrogen-oxygen flame. A similar procedure may be applied for $\mathrm{O}$ atom calibration. Here, in addition to the previous discussion, the collisional relaxation from the ${ }^{3} \mathrm{P}$ to the ${ }^{5} \mathrm{P}$ state has to be taken into account. All these considerations will be similar, though more complicated, for hydrocarbon flames, provided the respective experimental data will be available. 


\section{Acknowledgement}

We are grateful to the Stiftung Volkswagenwerk which provided part of the equipment.

\section{References}

[1] W.K. Bischel, B.E. Perry and D.R. Crosley, Appl. Opt. 21 (1982) 1419.

[2] R.P. Lucht, J.T. Salmon, G.B. King, D.W. Sweeney and N.M. Laurendeau, Opt. Letters 8 (1983) 365.

[3] M. Alden, H. Edner, P. Grafstrom and S. Svanberg, Opt. Commun. 42 (1982) 244

[4] A.W. Miziolek and M.A. DeWilde, Opt. Letters 9 (1984) 390.

[5] J.E.M. Goldsmith, Opt. Letters 7 (1982) 437.

[6] J.E.M. Goldsmith, J. Chem. Phys. 78 (1983) 1610.

[7] J.E.M. Goldsmith, 20th Symposium (International) on Combustion, The Combustion Institute, Pittsburgh (1984) p. 1331.

[8] P.J.H. Tsjossem and T.A. Cool, Chem. Phys. Letters 100 (1983) 479

[9] M. Alden, A.L. Schawlow, S. Svanberg, W. Wendt and P.-L. Zhang, Opt. Letters 9 (1984) 211.

[10] J.E.M. Goldsmith, Opt. Letters 10 (1985) 116.
[11] P.W. Fairschild, G.P. Smith and D.R. Crosley, J. Chem. Phys. 79 (1983) 1795 ,

[12] R.A. Copeland and D.R. Crosley, J. Chem. Phys., to be published.

[13] U. Meier, H.-H. Grotheer and Th. Just, Chem. Phys. Letters 106 (1984) 97.

[14] C.J. Howard, J. Phys. Chem. 83 (1979) 3, and references therein.

[15] D.R. Crosley and W.K. Bischel, Phys. Rev. A30 (1984) 1546.

[16] L.F. DiMauro, R.A. Gottscho and T.R. Miller, J. Appl. Phys. 56 (1984) 2007.

[17] M. Alden, H.M. Hertz, S. Svanberg and S. Wallin, Appl. Opt. 23 (1984) 3255.

[18] W.L. Wiese, M.W. Smith and B.M. Glennon, Atomic Transition Probabilities, NSRDS NBS4 (Natl. Bur. Std., Washington, 1966).

[19] S. Kröll, H. Lundberg, A. Persson and S. Svanberg, Phys. Rev. Letters 55 (1985) 284.

[20] J.E. Solarski and W.L. Wiese, Phys. Rev. A135 (1964) 1236 .

[21] T.I. Quickenden, S.M. Trotman, J.A. Irwin and D.F. Sangster, J. Chem. Phys. 71 (1979) 497.

[22] R.P. Lucht, D.W. Sweeney and N.R. Laurendeau, Combustion Flame 50 (1983) 189.

[23] J. Warnatz, Ber. Bunsenges. Physik. Chem. 82 (1978) 834.

[24] J. Warnatz, in: Combustion chemistry, ed. W.C. Gardiner Jr. (Springer, Berlin, 1984) p. 197. 